Document downloaded from:

http://hdl.handle.net/10251/80876

This paper must be cited as:

Pastor Soriano, JV.; García Oliver, JM.; García Martínez, A.; Pinotti, M. (2016). Laser induced plasma methodology for ignition control in direct injection sprays. Energy Conversion and Management. 120:144-156. doi:10.1016/j.enconman.2016.04.086.

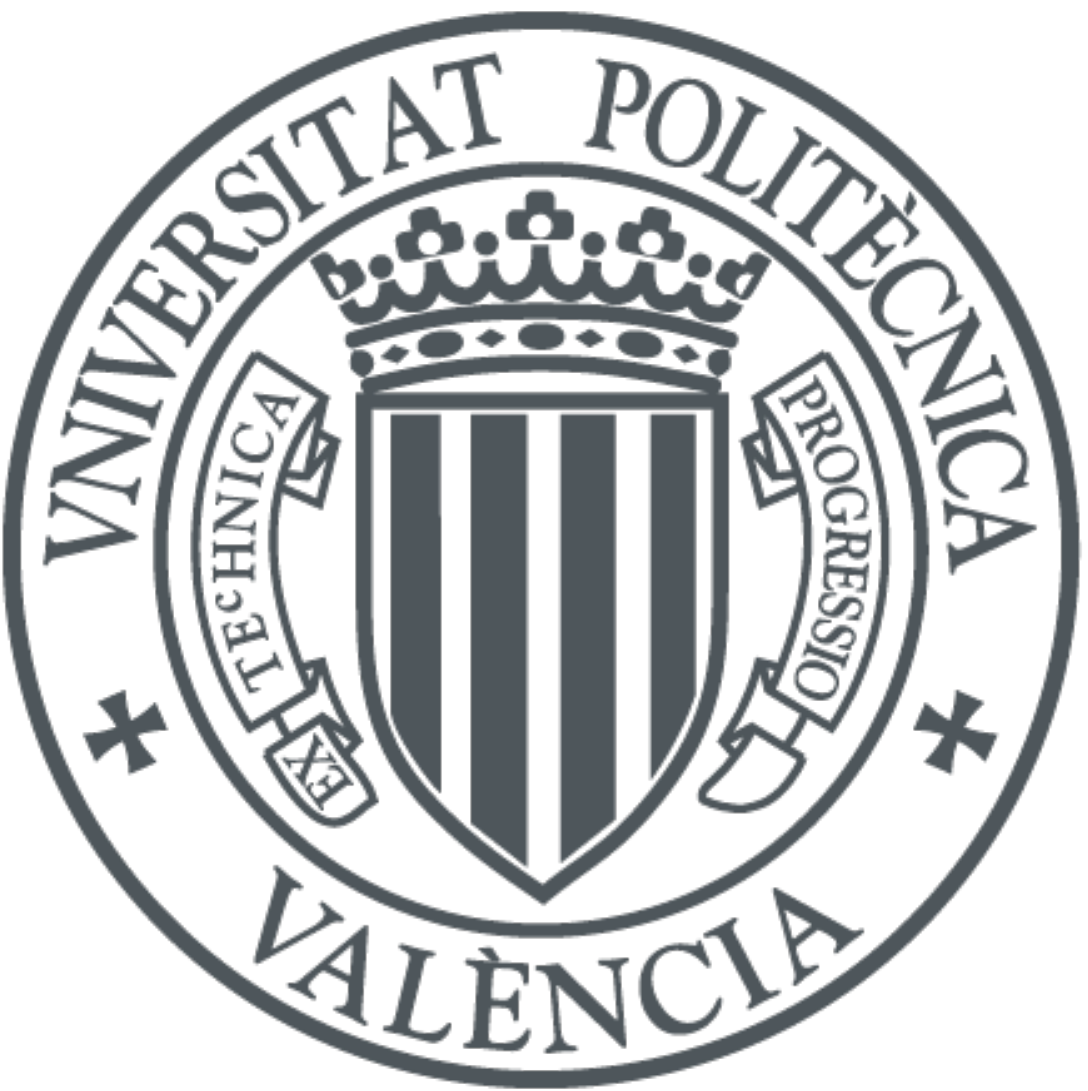

The final publication is available at

http://dx.doi.org/10.1016/j.enconman.2016.04.086

Copyright Elsevier

Additional Information 


\section{Laser Induced Plasma methodology for Ignition Control in Direct}

\section{Injection Sprays}

\section{Authors}

José V. Pastor, José M. García-Oliver, Antonio García, Mattia Pinotti

\section{Affiliation}

CMT Motores Térmicos - Universitat Politècnica de València, Camino de Vera s/n, 46022, Valencia, Spain.

\section{Corresponding Author}

Dr. José V. Pastor

CMT - Motores Térmicos /Universitat Politècnica de València

\section{jpastor@mot.upv.es}

\section{HIGHLIGHTS}

Laser Induced Plasma Ignition system is designed, optimized and then applied to a Diesel Spray

A methodology for the quantification of the ignition system effectiveness and reliability is proposed

The ignition system was optimized in atmospheric and engine-like conditions

Higher system effectiveness is reached with higher ambient density

The system is able to ignite a Diesel spray with full success rate, stabilizing the ignition delay if compared to the auto-ignition reference case 


\section{KEYWORDS}

Laser Plasma Ignition, Ignition System Reliability Quantification, Laser Ignition Optimization, Laser Induced Plasma Imaging, Diesel Spray provoked ignition.

\section{ABSTRACT}

New combustion modes for internal combustion engines represent one of the main fields of investigation for emissions control in transportation Industry. However, the implementation of lean fuel mixture condition and low temperature combustion in real engines is limited by different unsolved practical issues. To achieve an appropriate combustion phasing and cycle-to-cycle control of the process, the laser plasma ignition system arises as a valid alternative to the traditional electrical spark ignition system. This paper proposes a methodology to set-up and optimize a laser induced plasma ignition system that allows ensuring reliability through the quantification of the system effectiveness in the plasma generation and positional stability, in order to reach optimal ignition performance. For this purpose, experimental tests have been carried out in an optical test rig. At first the system has been optimized in an atmospheric environment, based on the statistical analysis of the plasma records taken with a high speed camera to evaluate the induction effectiveness and consequently regulate and control the system settings. The same optimization method has then been applied under engine-like conditions, analyzing the effect of thermodynamic ambient conditions on the plasma induction success and repeatability, which have shown to depend mainly on ambient density. Once optimized for selected engine conditions, the laser plasma induction system has been used to ignite a direct injection Diesel spray, and to compare the evolution of combustion with that of a conventional auto-ignited Diesel spray. 


\section{NOMENCLATURE}

$\begin{array}{ll}\text { EGR } & \text { Escape Gas Recirculation } \\ \text { HCCI } & \text { Homogeneous Charge Compression Ignition } \\ \text { PCCI } & \text { Premixed Charge Compression Ignition } \\ \text { SIDI } & \text { Spark Ignited Direct Ignition } \\ \text { UV } & \text { Ultraviolet } \\ \text { IR } & \text { Infrared } \\ \text { Rpm } & \text { Revolutions per Minute } \\ & \\ \text { Nd:YAG } & \text { Neodymium-doped yttrium aluminium garnet } \\ \text { TIPC } & \text { Top Dead Center } \\ \text { CMOS } & \text { Complementary metal-oxyde-semiconductor } \\ & \\ & \end{array}$




\section{INTRODUCTION}

Internal combustion engines play a fundamental role in the society, representing the primary source of equipment for transportation and energy production industry and also one of the principal sources of different pollutants. For this reason, even a slight improvement in its emission control and limitation will impact considerably on the reduction of overall emissions from the environment. With this main objective, researchers across the world are focused on new combustion modes for compression ignition $(\mathrm{Cl})$ engines [1]. These new combustion concepts can be achieved using different strategies, but with the common intention of shifting towards lean fuel mixture conditions [2] and to maintain low combustion temperature [3], typically with medium and high level of exhaust gas recirculation (EGR) [4], with the objective of decoupling the injection and combustion phases [5]. The higher thermal efficiency can be achieved with lower heat loss and high compression efficiency, besides it decrease pollutants, particularly $\mathrm{NO}_{\mathrm{x}}$ and soot. Combustion concepts based on partially to fully premixed lean mixtures are commonly known as Homogeneous Charge Compression Ignition ( $\mathrm{HCCl}$ [6], Premixed Charge Compression Ignition (PCCl), etc. While important emission benefits can be achieved, these combustion concepts present some practical issues which should be investigated before they can be implemented in internal combustion engines. One of the limitations that is affecting both $\mathrm{PCCl}$ combustion strategy-based engines and modern lean-burn spark-ignited direct-injection (SIDI) engines is represented by the possibility for achieving an appropriate combustion phasing and cycle-to-cycle control of the combustion process. Now, considering an application for a common electrical-spark ignition system as igniter and combustion stabilizer in the new developed combustion modes, various ignition system drawbacks should be investigated. An electrical spark plug generates a plasma when current of electrons surges across the gap that occurs between two electrodes by applying high voltage. In the operating range and local conditions of these combustion strategies 
the electrical-spark ignition system, trying to ignite mixtures that can rapidly fall outside of the ignition stability ranges, can present misfiring and not improving the combustion stability [7] as desired. Moreover, the presence of high velocities and turbulent fluctuations at the spark gap combined with long spark duration times (few milliseconds) [8] can cause the spark channel to become highly stretched [9] , leading to the presence of a wide range of local equivalence ratios and velocity conditions [10]. Furthermore, the spark plug electrodes themselves can also influence initial kernel development, quenching early flame development, disrupting in-cylinder flows, and promoting asymmetric flame propagation [11]. Finally, the electrodes are also prone to spray wetting and fouling, becoming a source of soot formation [12].

For this reason, some valid alternatives to the electrical discharge for the generation of a plasma spark have been investigated by several authors [13] [14]. In particular, considering results of studies already carried out back in the decade of the '60 on laser induced ionization and breakdown of gases [15] [16], the technological advance reached by the modern laser systems has permitted the progress of studies for the development of a laser plasma spark ignition. Q-switched lasers can deliver short-pulse and high intensive radiation emissions from the UV to the nearinfrared spectral region and are well known for their ability of generating a so called non-resonant breakdown in different gaseous media. Focusing the beam below certain diameter, depending on the laser emission power and beam quality, the local energy density threshold for the breakdown of a specific gas can be overcome in the focal region. This threshold does not only depend on the media composition, but experimental [17] [18] and theoretical [19] analyses show that, for wavelengths from the UV to the near IR region, it decreases with increasing ambient pressure. This pressure dependence is particularly favorable for engine applications, where the combustion chamber high pressure should facilitate the breakdown event with lower energy density concentration. Furthermore, the elimination of the spark electrodes removes a local heat sink just 
from the kernel development region, allowing better energy transfer from the plasma to the developing kernel. Weinberg et al. [20] first reported the ability of such laser induced plasma (LIP) for igniting combustible mixtures, whilst Dale et al. [21] performed the first experiments concerning a laser-ignited internal combustion engine demonstrating successful operation, also at leaner mixtures than the possible reached with the conventional electrical spark plug. Decreased ignition delay times have been observed for laser-induced sparks in comparison with conventional electric sparks [11]. Laser-ignition has also been observed to produce overdriven flame speeds, demonstrated in quiescent homogenous laser-ignited mixtures to produce flames that can momentarily propagate up to 20 times faster than the unstretched laminar flame speed [22]. Consequently, laser spark ignition application has the potential to shorten combustion duration and reduce cycle-to-cycle variation, which is the main drawback of the new combustion modes. Another significant benefit is that the laser-spark location is adjustable, allowing the ignition location to be optimized by positioning the ignition kernel where ideal equivalence ratio and velocity conditions exist for robust kernel development and flame propagation. Nonetheless, despite of its clear benefits, there is a lack in terms of the LIP system characterization to ensure the creation a proper plasma discharge when is required. Moreover, a systematic method to quantify the reliability of the system is not always found.

Down these considerations about the potential and recent interest in the laser induced plasma (LIP) spark ignition and its application to direct injected sprays applied in new $\mathrm{Cl}$ combustion modes [23] [24] [25], this paper proposes an experimental study to find a method for guaranteeing the plasma induction system optimization for its specific application as ignition system to internal combustion engines. This optimization was reached through a preliminary study performed on the effectiveness of the optical system in the breakdown generation in different typical engine-like thermodynamic conditions. Such kind of study and setup optimization method 
is considered fundamental in order to first obtain a high reliability optical system for the plasma induction that should be later applied to forced ignition studies, in order to have the adequate consideration of eventual misfire events.

\section{EXPERIMENTAL SETUP}

In the present section, a description on the test facility including the different systems employed for the study is made. Experiments were conducted in an optical test rig equipped with adequate optical accesses that made it possible for the laser beam to be focused in the combustion chamber to induce plasma on the spray axis.

\subsection{Experimental Facility}

\subsubsection{Optical Test Rig}

The optical test rig is a modified port scavenging two-stroke single cylinder direct injection Diesel engine (Jenbach JW50), with three-liter displacement, 15.8:1 compression ratio and motored at the low engine speed of 500 RPM with a dynamo brake that runs as an electrical engine. Intake and exhaust are managed by transfers on the liner and the cylinder head was adapted to offer various optical access to the combustion chamber [26] [27]. The cylinder head and engine temperature are both controlled via coolant recirculation. A cylindrical combustion chamber was designed specifically to avoid spray wall impingement and presents, as showed in Figure 1, an upper port where the injector is mounted for lateral accesses, to allow injection of isolated sprays with axial single-hole nozzles and permitting easy control over the plasma position along the vertical spray axis for the developing of an adequate method for the setup optimization. The combustion chamber is also provided with 4 large orthogonal access, one of which is used for 
mounting a pressure transducer to record the in-chamber pressure during tests, both for system control and data acquisition. The other remaining entrances, equipped with three oval shaped fused silica windows of $30 \times 81 \times 28 \mathrm{~mm}$, guarantees an optimal optical access to the chamber permitting the visualization of nearly entire spray or flame length and the focusing of the laser beam inside the chamber.

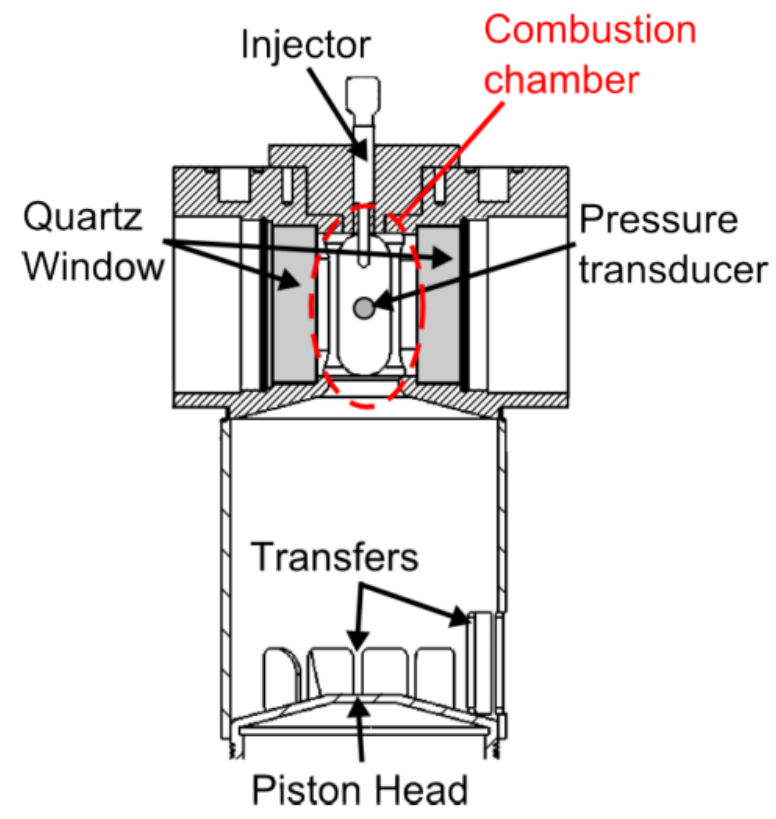

Figure 1 - Scheme of the optical test rig engine's head adapted to allocate optical access. Can be appreciated the position of the injector, pressure transducer and fused silica quartz window.

The test rig permits independent regulation of ambient temperature, pressure and gas composition, which makes it possible to replicate a wide range of thermodynamic conditions as in modern passenger car engine. The intake temperature is controlled by two sets of electrical resistors, one of them located just before the intake port while the intake pressure is controlled by an external compressor. In order to keep in-cylinder conditions constant, the engine is operated under skip-fired mode, so that an injection takes place each 30 cycles. This guarantees that incylinder conditions are not influenced by residual gases from the previous cycle.

\subsubsection{Injection System}


The employed injection system was a Bosch common rail injector with a cylindrical single-hole of 140um that was previously characterized geometrically and hydraulically in a commercial EVI_IAV system (Bosch method). Standard European Diesel fuel was used for this work, injected at a rail pressure of $50 \mathrm{MPa}$. The measured Injection Rate is plotted in Figure 2. The injection system fundamental characteristics are summarized in Table 1.

\begin{tabular}{lc}
\hline \multicolumn{2}{l}{ Bosh Single Nozzle Injector Specifications } \\
\hline Injection Pressure & 500 bar \\
Fuel Injected & Diesel B \\
Nozzle Diameter & $140 \mu \mathrm{m}$ \\
Discharge Coefficient & 0.833 \\
Velocity Reduction Coefficient & 0.9819
\end{tabular}

Table 1 - Bosch Injector principal characteristics measured at the 2 injection pressure configuration used for the laser plasma ignition tests

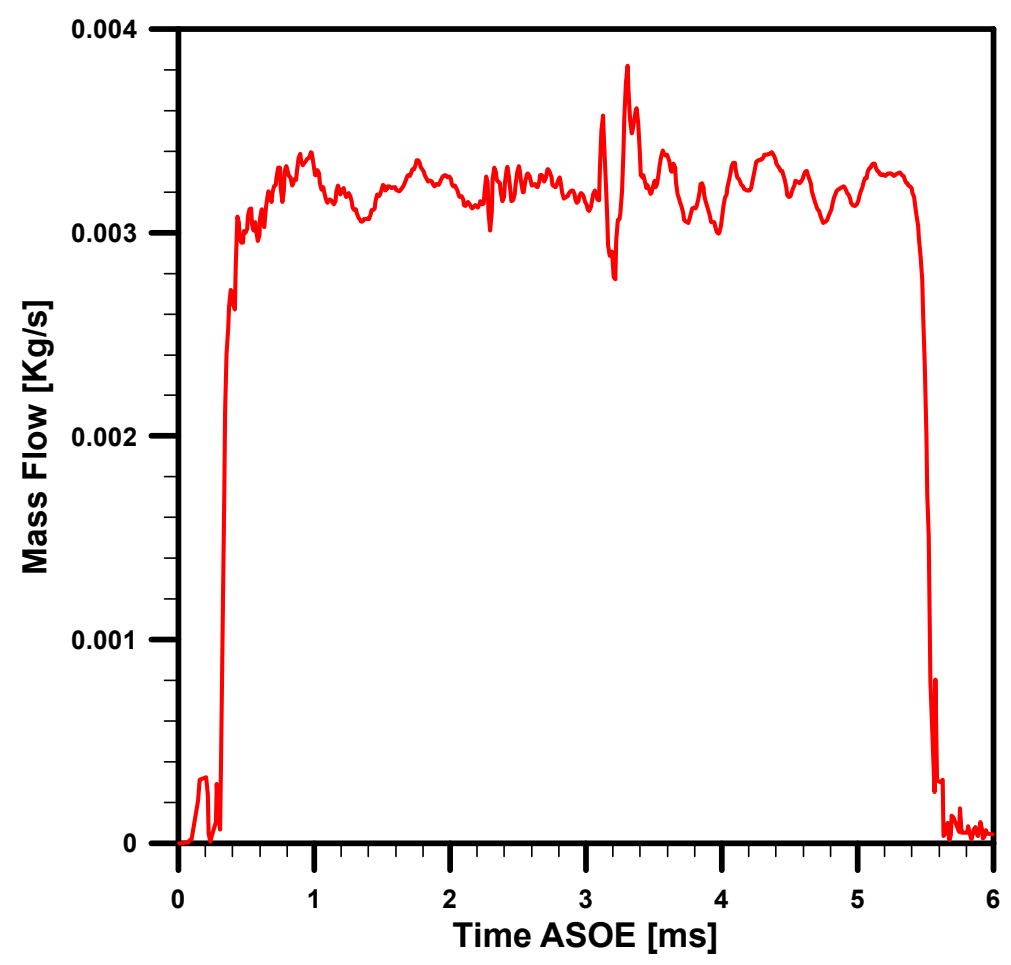

Figure 2 - Mass Flow Rate measured for the injection configuration used for the laser plasma ignition tests. 


\subsection{Optical Devices}

In the next paragraphs, the optical devices used for the laser plasma induction system and image acquisition system applied to the system reliability characterization and combustion visualization are described in detail.

\subsubsection{Laser Plasma Induction System}

The plasma was induced using a $10 \mathrm{~Hz}$ flashlamp pumped Nd:YAG Laser (Continuum Surelite II model) operated at a pulse energy lower than $350 \mathrm{~mJ}$ at $1064 \mathrm{~nm}$. The laser output energy was carefully controlled by the Q-switch delay tuning of the system. The optical beam path required to focus the Laser emission into the cylinder head was defined using various laser-line mirrors with a maximum reflectivity in the operating wavelength to minimize optical losses and beam distortion. The beam focusing in the combustion chamber was performed with an $\mathrm{nBK}-7$ lens of $300 \mathrm{~mm}$ focal length. The whole system was designed to allow the free positioning of the focal point of the focusing lens into the combustion chamber, in order to control de plasma induction location with respect to the theoretical volume occupied by the spray during the injection. For this reason, the vertical and horizontal position of the focusing lens was controlled by moving two perpendicular platforms. The laser characteristics are given in Table 2. A view of the optical setup including the test facility, the focusing optics of laser plasma induction and the visualization system is reported in Figure 3.

\section{Continuum Surelite II Laser}

\begin{tabular}{lc}
\hline \multicolumn{2}{c}{ System Specifications } \\
\hline Principal Head Diameter & $6 \mathrm{~mm}$ \\
Repetition Rate & $10 \mathrm{~Hz}$ \\
Pulse width & $15-20 \mathrm{~ns}$ \\
Energy & $<350 \mathrm{~mJ}$
\end{tabular}




\begin{tabular}{lc}
\hline \multicolumn{2}{c}{ System Settings } \\
\hline Flashlamp Discharge Voltage & $1.52 \mathrm{kV}$ \\
Q-Switch Delay & $198 \mu \mathrm{s}$ \\
\hline
\end{tabular}

\section{Measured Emission Energies}

\begin{tabular}{ccc}
\hline Wavelength & Energy & Power \\
$1064 \mathrm{~nm}$ & $660 \mathrm{~mJ}$ & $6.6 \mathrm{~W}$
\end{tabular}

Table 2 - Nd:YAG pumped q-switched laser used for the plasma induction specifications, settings and measured emission energy

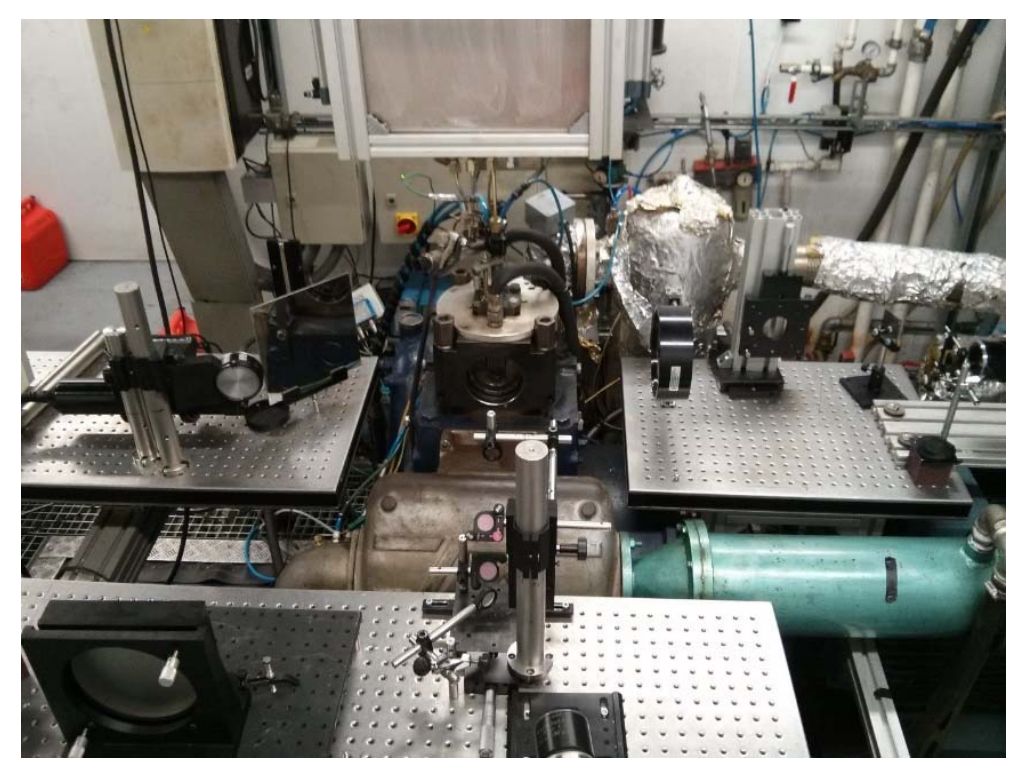

Figure 3 - View of the experimental facility. In the image center, the engine cylinder head is observed. The schlieren arrangement consists of the illumination (left) and collecting systems (right). Finally, the last part of the laser beam guiding and focusing system is observed on the center bottom part of the image.

\subsubsection{Image Acquisition System}

A unique visualization system was designed for the application of two different optical techniques, which will be detailed described in the next section. The device employed for the image acquisition was a high speed CMOS Phantom V12.0 camera, while Illumination was provided by a 300W Xe continuous lamp (Karl Storz Xenon Nova 300). A series of other optical elements was used for the visualization system setup and will be reported in the next section. 


\subsection{Experimental System Synchronization}

System synchronization was performed with the help of ad-hoc system especially designed to control both flash lamp and q-switch pulses of the laser system to ensure stable operating conditions and to minimize laser shot energy fluctuations. This system enabled synchronization of laser together with the camera, injection system and pressure transducer. A schematic in Figure 4 demonstrates the whole synchronization system applied during the engine tests.

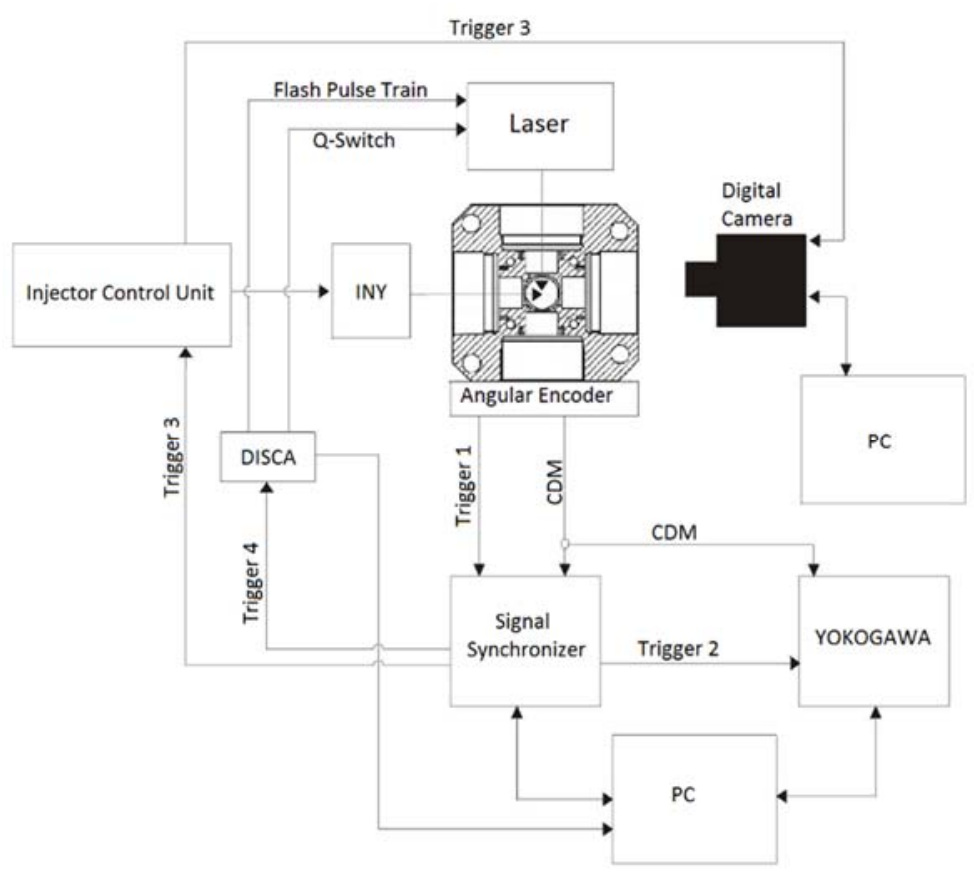

Figure 4 - Experimental control and measuring signal synchronization system employed during the tests performed in the optical test rig.

\section{EXPERIMENTAL METHODOLOGY}

This section will report the methodologies used for the experiment development in the laser ignition system optimization procedure and subsequent ignition tests. Natural luminosity visualization has been employed for registering plasma images when evaluating the performance of the laser induced plasma system in the absence of injection. The same technique is later used 
for spray ignition studies, to visualize soot radiation, both in the provoked and auto-ignition cases. Schlieren optical technique was also applied for combustion visualization in order to register the spatial location of the spray. This section describes the methodology for the selection of the right configuration for the laser plasma induction system elements and for the visualization techniques applied to the plasma and spray combustion imaging. It also describes the image processing method applied.

\subsection{Operating conditions}

The first tests realized for configuring the induction system and quantify its effectiveness were done in ambient air conditions. The alignment of the plasma generation system with the injector position in the combustion chamber has allowed the evaluation of the positional stability of the air breakdown. For the tests under engine-like conditions, the test matrix defined in terms of TDC pressure, temperature and density is reported in Table 3.

\begin{tabular}{|c|c|c|}
\hline Temperature $[\mathrm{K}]$ & Pressure [bar] & $\rho[\mathrm{kg} / \mathrm{m} 3]$ \\
\hline 900 & 53 & 20.8 \\
\hline 700 & 43 & 21.7 \\
\hline 800 & 53 & 23.4 \\
\hline 700 & 53 & 26.7 \\
\hline 700 & 63 & 31.8 \\
\hline
\end{tabular}

Table 3-Operating conditions of the engine at TDC used in the plasma induction effectiveness tests.

\subsection{Optical Set Up - Schlieren and Natural Luminosity Visualization}

A single optical setup was used for the plasma and spray combustion visualization by applying two different optical techniques, namely Schlieren visualization and Natural Luminosity. A schematic of the arrangement is shown in Figure 5. A unique visualization system was designed for the 
application of the two different optical techniques, by means of a high speed CMOS Phantom V12.0 camera. A $100 \mathrm{~mm} \mathrm{f:2} \mathrm{camera} \mathrm{lens} \mathrm{(Zeiss} \mathrm{Makro-Planar} \mathrm{T}^{*} 2$ ) was used to collect all the light into the camera sensor, allowing a very sharp definition of the focusing zone.

Only the camera was used when performing measurements of plasma images or spray soot radiation. On the other hand, for schlieren analysis a collimated light beam was used for the generation of the schlieren effect by focusing the light source (300W Xe continuous lamp, Karl Storz Xenon Nova 300) with a liquid fiber through a pin hole of $0.15 \mathrm{~mm}$, to form a light spot at the focal point of a $150 \mathrm{~mm}$ diameter spherical mirror with a focal length of $610 \mathrm{~mm}$. The mirror collimates the beam that then enters the combustion chamber reflected through another redirecting mirror.

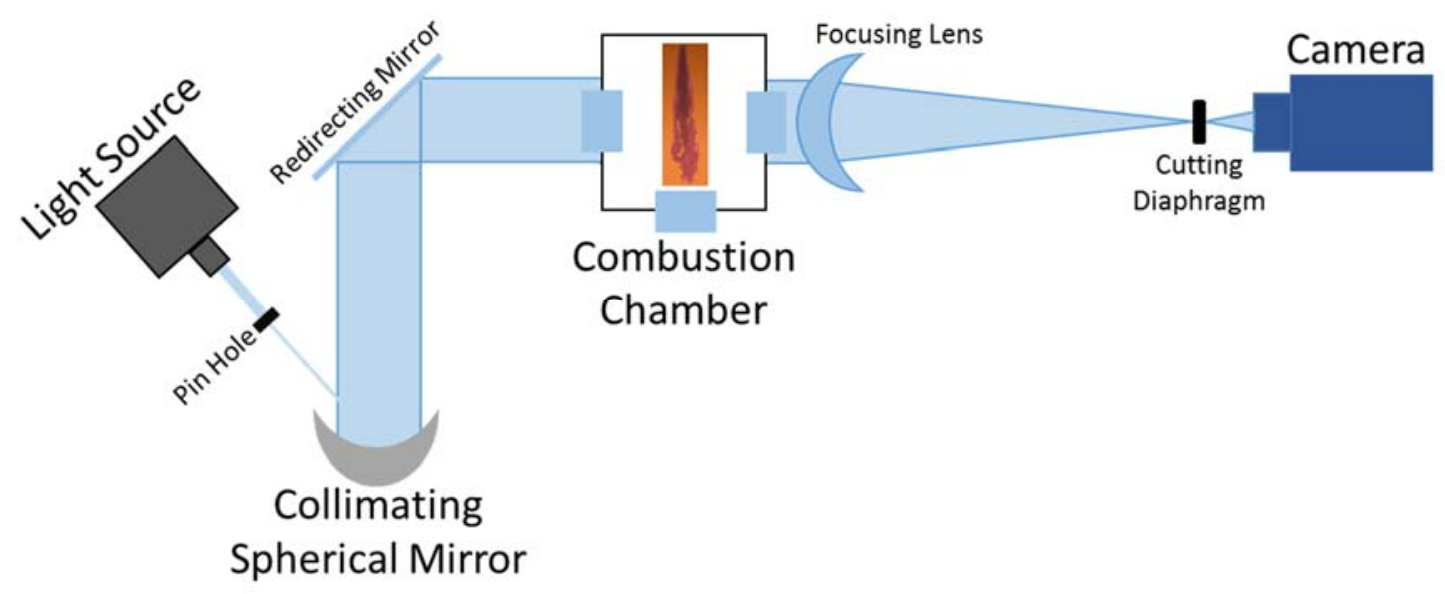

Figure 5 - Schematic representation of the optical system used for the Schlieren imaging acquisition.

On the other side of the combustion chamber light was collected by a $150 \mathrm{~mm}$ diameter lens with a focal length of $450 \mathrm{~mm}$, sufficient to guarantee a minimal light dispersion. A cutting diaphragm was positioned at the camera lens focal length to apply a spatial filtering to the focalized beam in the Fourier's plane. Both the light source and the cuttoff diaphragm were only used in schlieren visualization tests, the latter one being replaced by a neutral density filter when carrying out soot radiation visualization tests and air breakdown plasma visualization. 


\subsubsection{Schlieren Method}

The aim of this technique is to register images of spray combustion, particularly focusing on the determination of the spray penetration in the combustion chamber.
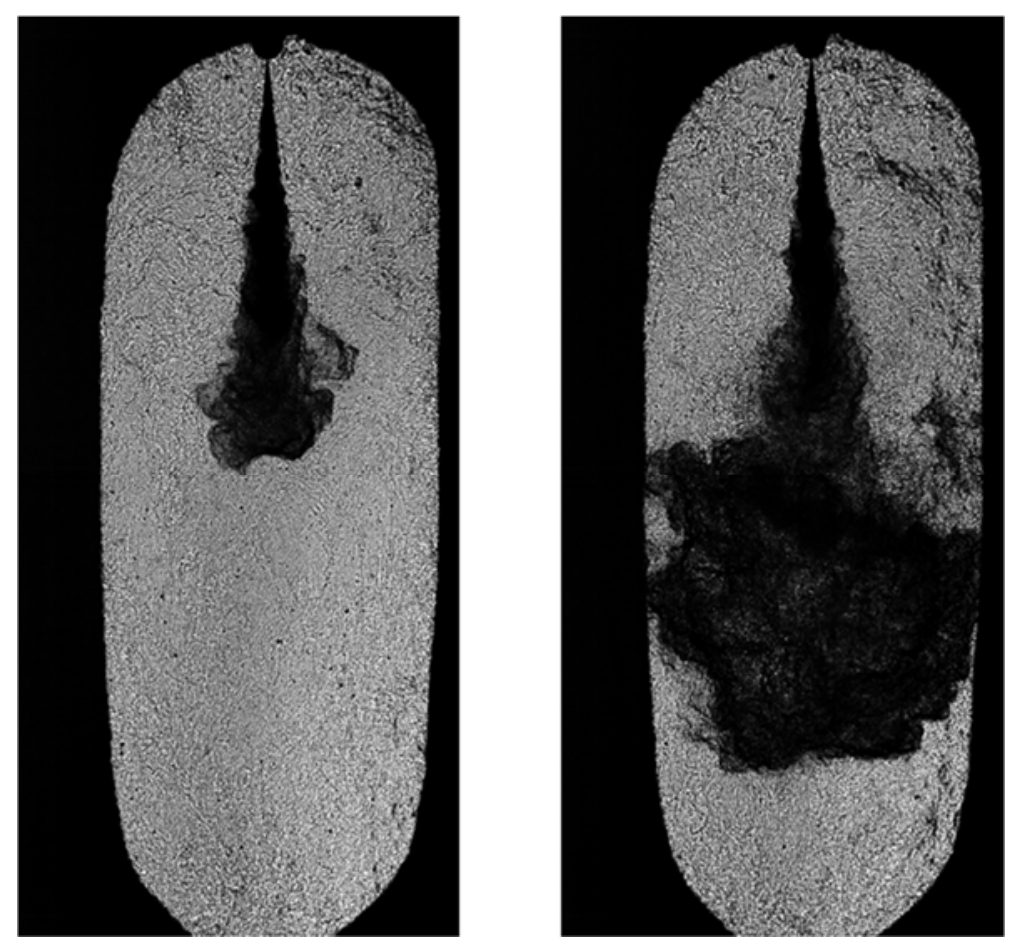

Figure 6 - Spray visualization as obtained from Schlieren Imaging method. Images showed for direct injection spray at 875us after the start of energizing (left picture), before the start of combustion, and at 3125us after the start of energizing (right picture) and after the start of combustion. Both images have been registered for natural auto-ignition processes of the Diesel spray.

The technique is based on the deviation effect caused by density gradients on a collimated light beam, which is visualized as light intensity gradients in the image plane. The magnitude of the deviation depends on the density gradients found through combustion chamber [28]. For this reason, zones with a high local density of the spray, such as its liquid phase (where light scattering also adds to the deviation effect) and the spray interphase, will result as darker zones on the image plane. While the spray penetrates and the fuel mixes up with the air, the density difference becomes less evident resulting in the image plane as gray zones, allowing the identification of spray volume and shape during the injection and combustion. The application of the method has 
made use of the optical setup presented before. Spray auto-ignition and provoked ignition cases were registered with the high speed CCD camera synchronized with the injection signal while the combustion chamber was continuously illuminated with the collimated beam. An example of the obtained images is reported in Figure 6.

\subsubsection{Natural Luminosity Method}

The aim of the method is to register a high intensity broadband emission. This method was used for two concrete cases: to register the flame soot emission and to register the laser induced plasma images.

\subsubsection{Soot radiation registration}

The registration of the broadband radiation produced by the incandescence of the soot particles has the objective of complementing the visualization of the spray combustion already realized with the Schlieren method comparing the auto-ignition with the laser plasma provoked ignition. The soot images were registered by maintaining the optical parameters of the setup and slightly modifying the camera acquisition parameters, where the shutter time was raised of $2 \mu$ s thanks to the application of a neutral density filter to limit the soot emission. The camera acquisition parameters for the combustion visualization applied techniques are reported in Table 4.

\begin{tabular}{ll}
\hline \multicolumn{2}{c}{ Phantom V12.0 CCD Camera Acquisition set-up } \\
\hline Image resolution & $384 \times 800 \mathrm{pix}$ \\
Pixel/mm ratio & $10.28 \mathrm{pix} / \mathrm{mm}$ \\
Acquisition Framerate & $16000 \mathrm{fps}$ \\
Image-Image Interval & $62.5 \mu \mathrm{s}$ \\
Exposure time (Schlieren Imaging) & $6 \mu \mathrm{s}$ \\
Exposure time (Natural Luminosity) & $8 \mu \mathrm{s}$
\end{tabular}




\subsubsection{Plasma Images Registration}

Visualization of the plasma formation is by registering its broadband at high intensity emission, has the aim to quantify the effectiveness of the plasma induction system and its reliability. Registering plasma images with a good spatial resolution and a fixed spatial reference permits not only to account for the overall effectiveness of the system in provoking the breakdown of the medium shot by shot, but also the positional stability of the induced plasma, which is another fundamental factor when the ignition capabilities of the system should be considered for a direct injection spray. The plasma generation tests were realized both in ambient air conditions and engine like conditions, as reported in Table 3. As mentioned above, such tests were carried out in the absence of fuel injection into the chamber. For every tested condition, the plasma induction was attempted at five different distances from the injector nozzle along the injector axis in the combustion chamber. Every induction position was spaced at $5 \mathrm{~mm}$ from the previous induction position. This variation of the plasma generation position has allowed also to test the vertical alignment of the system with the injector axis, corresponding with the fuel spray axis, ensuring the possibility to obtain plasma formation in the spray cone along all the combustion chamber volume. The spatial resolution obtained in the setup from the combination of the camera lens and collecting lens mounted outside the optical access was of 10.28 pixels $/ \mathrm{mm}$, enough to have a sufficient resolution of the interesting area while maintaining the possibilities to visualize the entire combustion chamber. The camera was synchronized with the laser pulse by the same trigger signal, virtually representing the start of energizing. To avoid possible synchronization errors, the camera was always fired earlier than the laser and was set up to register the maximum number of images possible in the selected time interval, each one of which with a minimum exposure time of $8 \mu$ s higher than the common plasma lifetime reported in literature (105 ns as reported in [29]) or, more in general, in the order of the same laser pulse duration [30]). 
Furthermore, Pickett et al. [25], for a similar optical set up, used comparable parameters of $10 \mu \mathrm{s}$ framing period and $4 \mu$ s exposure time for registering plasma and reports how the first valid image of plasma was registered $21 \mu \mathrm{s}$ after the laser pulse because, before that time period, the high intensity breakdown emission completely saturates the camera. Once the camera configuration is selected, the combination of the recording speed and shutter time were tuned up always to maintain a fixed image resolution of $384 \times 800$ pixels that allows to see the entire combustion chamber, as requested from the subsequent spray ignition tests, in order to be able to refer the induced plasma position with the volume effectively occupied by the spray. For each tested condition, 75 repetitions were performed. An example of the plasma imaging is reported in Figure 7.

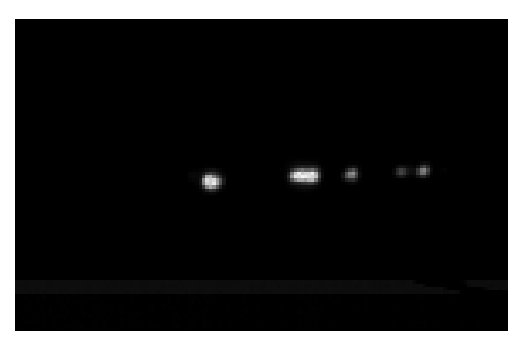

Figure 7 - Images of recorded plasma during the test realized for the laser induction system optimization. The images shows an example of multipoint induction.

\subsection{Plasma Image Processing}

The effectiveness of the system in the plasma generation was quantified through the plasma images processing, obtaining plasma probability maps such as reported in Figure 8 for the atmospheric air condition during a plasma vertical position variations. 

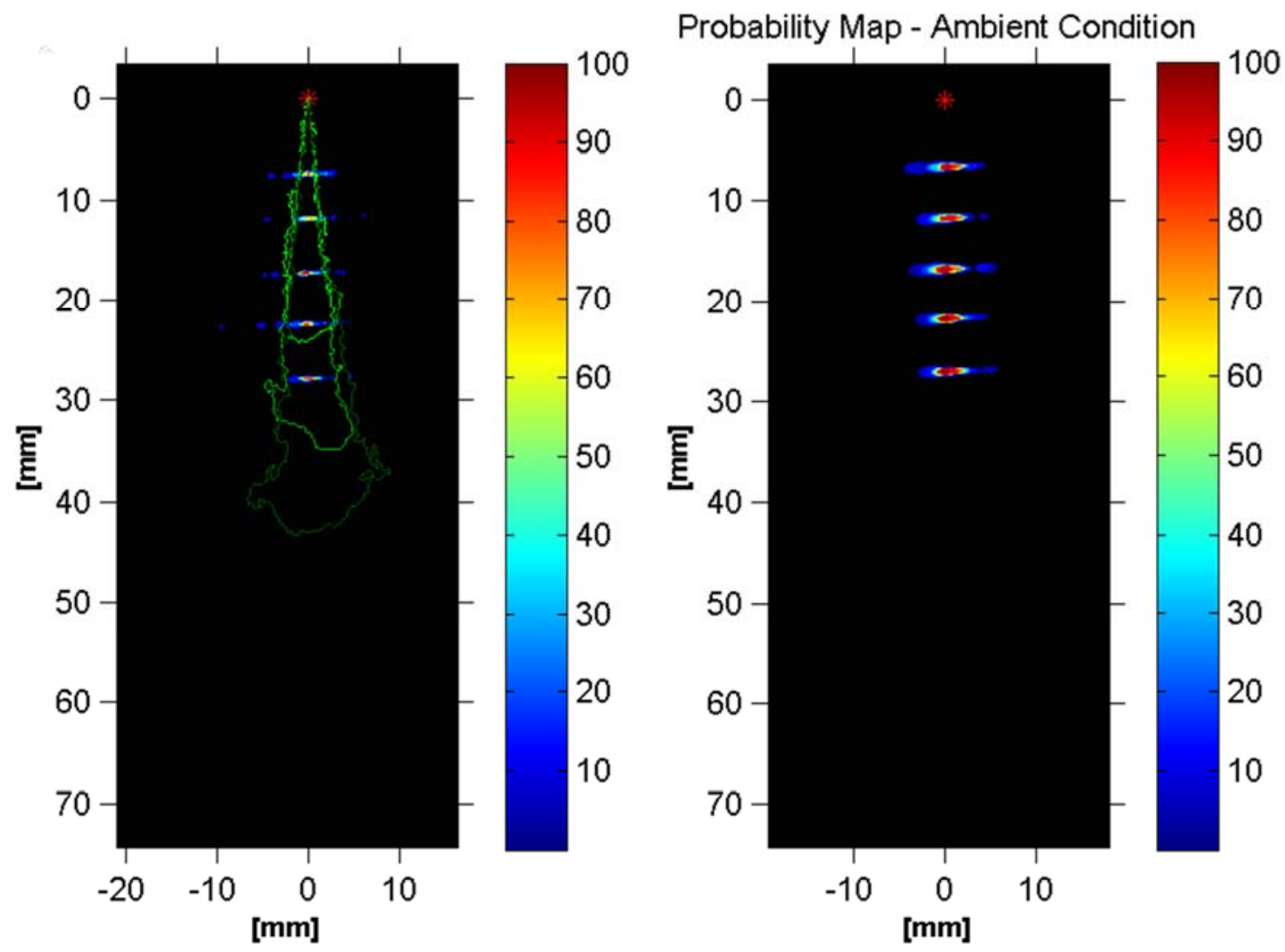

Figure 8 - - Plasma Generation Probability Maps. On the right the probability maps obtained for the plasma induction under atmospheric conditions, without fuel injection, at different distances from the injector nozzle that is indicated in the figure by an asterisk. On the right is reported the results for an engine-like condition case, this too without injection but where some examples of real spray contours have been reported as an indication of the volume occupied by a real spray cone during the injection event. The area of $81 \times 28 \mathrm{~mm}$ visible in the reported images is the total available access to the combustion chamber.

These probability maps represent the effectively calculated probability of finding plasma in a particular position of the combustion chamber, with respect to the total plasma generation attempts. Such maps were obtained from the post processing of the plasma images registered with the CCD camera through a specific algorithm. For every image registered, the algorithm first identifies plasma presence and, if detected, it segments the image by dividing the region occupied by the plasma emission from that of the background. This procedure was carried out, after a series of different processing attempts, using a fixed threshold value of $20 \%$ higher than the mean background digital level, both for the plasma presence detection and for the segmentation. The fixed threshold selected was considered to be optimal for the image segmentation thanks to the 
high intensity emission of the plasma in total black surroundings. The binary images where then accumulated and divided by the total number of breakdown attempts to estimate plasma occurrence probability. A visual schematization of the process followed by the image processing algorithm is reported in Figure 9. The results of this operation, shown in a $0-100 \%$ color map, represent the number of times that plasma could be detected at a specific pixel position, and allows the estimation of both the overall breakdown success rate and the positional stability of the induction event. Both will be reported later in the results paragraph.

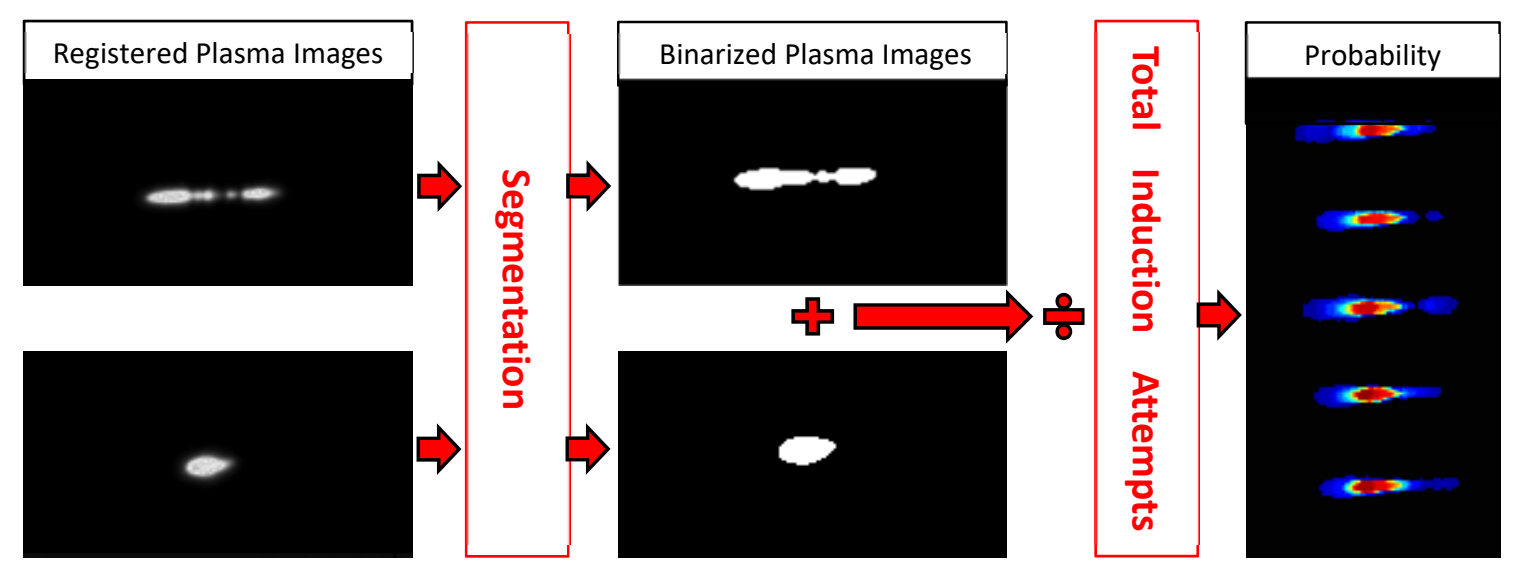

Figure 9 - Schematization of the process followed by the algorithm used to obtain Plasma probability maps. Only the images with plasma were first selected among all the registered repetitions, then binarized in order to distinguish background from the area occupied by the plasma emission. At this point the images are cumulated and divided by the total number of induction attempts. The results are then plotted in a color-map showing in red the $100 \%$ plasma occurrence and in blue the lowest probability to find plasma in a pixel.

The relatively small size of the registered plasma when compared with the total resolution of the registered image has not allowed any discrimination between the real plasma kernel zone and a blooming effect zone registered by the camera sensor due to the high intensity emission. In any case, for the purpose of this study, the spatial resolution was enough to determine whether the plasma generation position was or not included within the spray boundaries, as represented in Figure 8 (right). 


\subsection{Laser Plasma Induction System Settings and Configurations}

In the design of a laser plasma induction system through the focalization of a pulsed laser beam, the objective is to obtain enough energy density at the focal spot to provoke a molecular breakdown of the medium. It has to be taken into account that the objective of the laser plasma induction system configuration tuning was to find the minimum possible energy density configuration to ensure $100 \%$ effectiveness in the plasma generation. The application of higher energy density level to the investigated area will actually provoke instability in terms of the spatial position of the molecular breakdown event inside a bigger critical volume. This behavior has to be avoided since the position of the plasma in the combustion chamber is considered an important parameter in the current research. Different studies report how the breakdown minimal energy threshold of a medium could be affected by various parameters of the medium itself, such as local pressure, density, air flux velocity [22], [31], [30]. Moreover, as reported from various authors [32], [33], [30], the definition of a minimum threshold level of energy breakdown of a medium is also controversial and puts in evidence the stochastic nature of the molecular breakdown itself. Meanwhile, it is also known how the plasma induction phenomena results practically independent on parameters such as laser pulse duration and energy emission [34], but strongly depended on the focal length of the laser focusing lens [30], being more difficult to induce plasma with larger focal lengths. For these reasons, an a-priori determination of the required characteristics for a laser plasma induction system results quite complicated and it is not so reliable, once taken in account the important variations that the minimum breakdown energy threshold can suffer depending on the local conditions considered. So, the selection of the component for the realization of the laser plasma induction system was then based on the possibility to generate plasma in atmospheric air conditions, based on the consideration that under engine-like conditions (high pressure and temperature coupled with the presence of fuel particles instead of 
pure air) breakdown energy limit could only be lower. Moreover, a practical limitation depending on the configuration of the experimental facility had to be respected, so that the minimum possible distance from the center of the combustion chamber to the nearest position where the focusing lens could be mounted was around $300 \mathrm{~mm}$, forcing to use a lens of that minimum focal. This limitation in the achievable focal spot volume, has raised the requirements in terms of laser power for the plasma induction system. Finally, the laser system used is enough to ensure a local energy density in air of $1.3 \times 10^{9} \mathrm{~J} / \mathrm{m}^{3}$ with a pulse power output of $300 \mathrm{~mJ}$ at $1064 \mathrm{~nm}$, consistent values with the one reported by different authors in similar laser plasma induction configurations [22] [30].

\subsection{Pressure Signal Processing}

The in-cylinder pressure evolution registered during the combustion tests was principally used for the quantification of the spray ignition delay, in order to determine if the laser plasma ignition system was provoking effectively an anticipate ignition of the Diesel spray before the natural autoignition event. An AVL GU13P pressure transducer coupled to a Kistler 5011 charge amplifier is used to measure the cylinder pressure with a sampling frequency of $36 \mathrm{kHz}$ (every 0.20 CAD). 


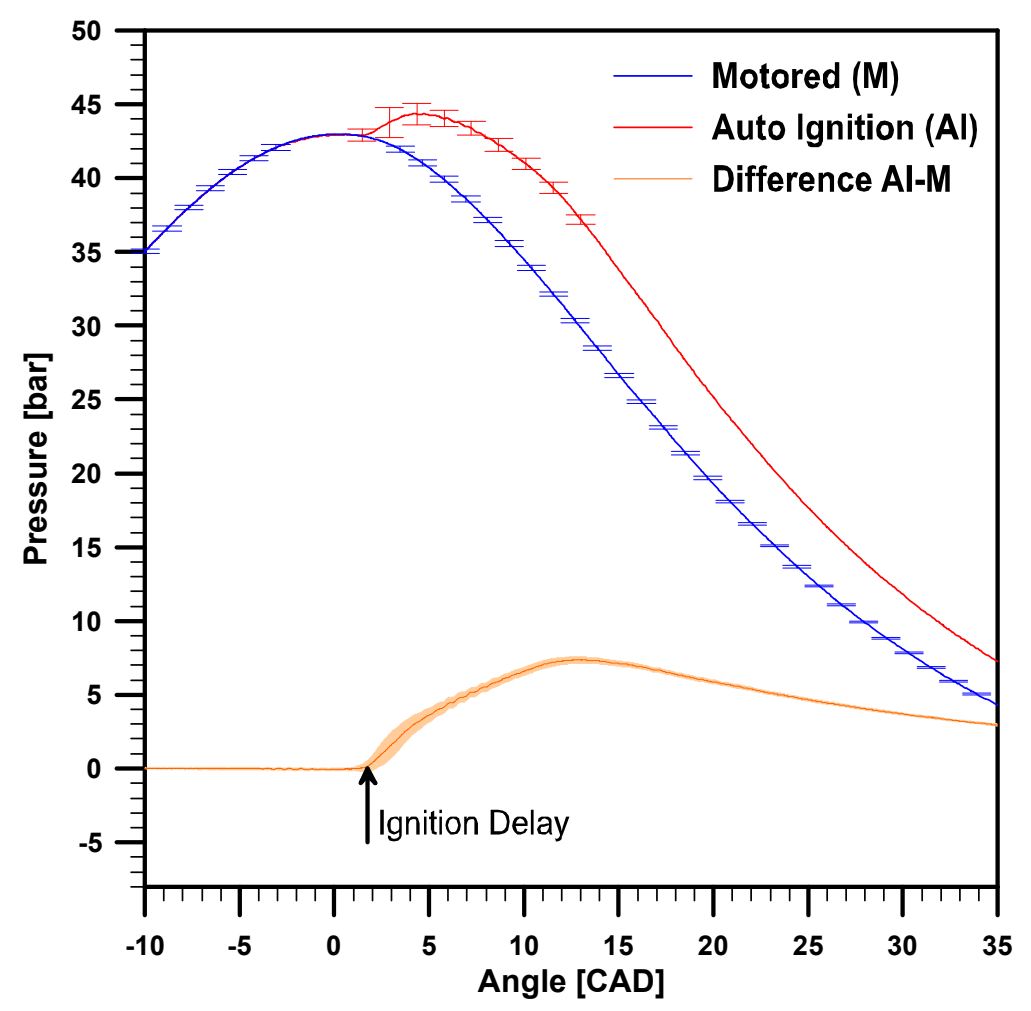

Figure 10 - In cylinder pressure evolution comparison between motored and combustion registered cases. The curves showed here are an average of 50 repetitions. The standard deviation is reported as vertical error bars along the average curve. The difference between the shot to shot stability of the pressure curves can clearly be appreciated. The difference between the two pressure curves is also reported at the bottom, as a clear indicator of the start of combustion.

Every registered pressure acquisition consists of a pair of engine cycles, the first one always with the engine motored without fuel injection. The direct comparison of the two consecutive pressure curves, one with combustion and one with the motored engine, permits the derivation of the ignition delay as the time when the in-cylinder pressure evolution starts to raise over the engine motored compression pressure curve, as can be seen in Figure 10.

\section{EXPERIMENTAL RESULTS}

This section reports the experimental results obtained through the plasma induction system optimization process and from the application of such system to a direct injection spray. 
The application of a high reliability ignition system is considered as a matter of major importance in any engine application, especially if the principal objective is to study its impact on the combustion development in comparison with a conventional spark plug. Indeed, a high system effectiveness in terms of plasma formation, timing and spatial precision allows discarding from the causes of eventual observable variations between different ignition conditions that such a system is allowing to test, any failure in the breakdown generation. This allows ascribing such variations just to the fuel spray local conditions of the ignition region discarding a second order factor of uncertainty. To get this sort of high-reliability system, both optical system settings and thermodynamic conditions in the combustion chamber were considered in a parametric variation study to find the highest laser plasma formation effectiveness. This study was performed by taking plasma images with the high speed CMOS camera synchronized with the laser system by an external trigger, which virtually wants to simulate the ignition trigger signal. The tests were carried out both under engine-like and atmospheric ambient conditions, in the latter case with and without the optical access window mounted as an element of the laser beam path.

\subsection{Laser Plasma Induction System Reliability Optimization Study}

The main design for the plasma induction system was first selected by the theoretical consideration about breakdown thresholds and energy density at the focal spot as reported in section 3.3. This setup was then tested in different experimental conditions where his reliability in terms of with different plasma induction capability and plasma position stability was quantified. The results of the study are reported in this section.

\subsubsection{Laser Plasma Induction System effectiveness in atmospheric air condition.}

The first test was performed in atmospheric conditions, with the complete optical redirection and focusing system mounted, with the aim of optimizing the optical setup for the plasma generation 
for maximum effectiveness. Indeed, the large focal length of the lens $(300 \mathrm{~mm})$ employed in the system, forced by the test rig geometry, was one of the biggest limitation of this kind of application, since it limits the minimum size of the spot and its depth of focus. Various authors report how the minimization of the focal spot's dimensions represents a primary importance factor for the success of a laser induced breakdown event, highlighting its strong dependence on the lens focal length [30] [31] [35]. In fact, most of the studies carried out in this research field report optical set-ups performed with focal lengths far shorter than the $300 \mathrm{~mm}$ used for this study. Besides that, using a higher energy beam has allowed to reach an optimal configuration. In fact, the results obtained from the plasma generation tests here reported in Figure 8 , has shown the possibility to reach the $100 \%$ effectiveness in plasma induction, both in terms of molecule breakdown effect and positional stability, with this configuration. Figure 8 (right) reports the obtained results for atmospheric air conditions with the fused silica glass window mounted as an element of the optical system in the laser beam path (results of tests performed without optical windows are omitted for brevity). The results are reported here as a probability map, indicating the probability of finding plasma in a certain position along the spray axis with respect to the total plasma generation attempts. Figure 11 reports the same results previously reported in the probability map of Figure 8 but just in terms of one-dimensional plots, where the horizontal axis represents the distance to the spray axis, where the beam is theoretically focused, while each profile corresponds to a different target position of the laser beam from the nozzle orifice. The effective dimension of the area where it is always possible to find induced plasma can be quantified in terms of such plots.

For each tested position 75 repetition attempts were recorded. Even if the spatial resolution of the registered images is not sufficient for the determination of the effective plasma dimensions, due to the impossibility of distinguishing between real plasma volume and blooming effect registered 
by the camera sensor, for the purpose of this study was more than enough to determine whether the plasma generation position was or not included within the spray boundaries. This was considered as the fundamental parameter to take in account in order to ensure the effectiveness of the designed ignition system. Looking at the plasma occurrence probability graph reported in Figure 11, it results clear that the system can reach a plasma generation effectiveness of $100 \%$ with excellent positional stability, in air at atmospheric conditions, for the chosen laser system and optical settings. The shape of the probability curve in the horizontal direction, with the highest generation probability always on the axis with respect to the borderline, is due to the variation of the plasma dimensions between subsequent firing attempts.

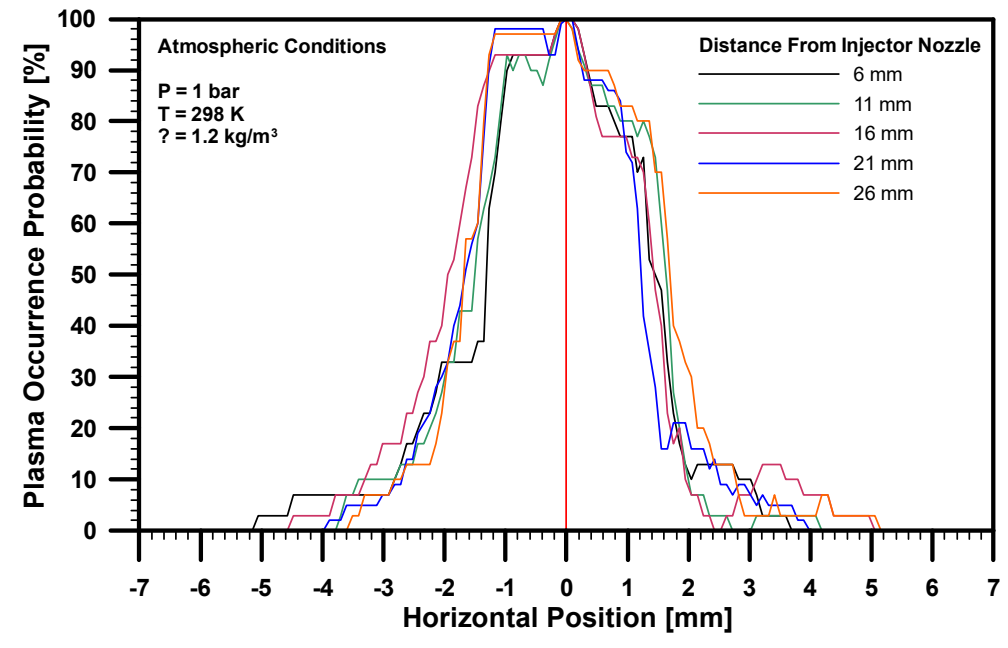

Figure 11 - Plasma Occurrence Probability as obtained from the probability map method is here reported just as the values obtained in the plasma generation plane with respect the injector nozzle position, located at $0 \mathrm{~mm}$. The graph shows the probability of inducting plasma in the focal axis and permits the determination of its positional generation stability.

\subsubsection{Laser Plasma Induction System Effectiveness under Engine-Like Conditions}

For the evaluation of plasma generation under engine-like conditions, tests were performed following exactly the same experimental procedure as earlier described for atmospheric conditions. The investigated in-cylinder conditions are combined with the respective overall success rate as shown in Table 5. The Success Rate (SR) is obtained as reported in Equation 1. 


$$
\text { Success Rate }=\frac{\text { Induction Succes Events }}{\text { Total Number of Induction Attempts }}
$$

Equation 1 - Overall Success Rate of Plasma Induction events

In addition to the results in Table 5, plasma occurrence probability graphs are depicted in Figure 12. It must be noted that the defined success rate only considers the possibility of ignition occurring, not the spatial repeatability, which is rather described in the plasma occurrence probability graphs.

\begin{tabular}{|c|c|c|c|c|c|c|}
\hline Case Name & $\begin{array}{c}\text { Pressure } \\
{[\mathrm{bar}]}\end{array}$ & $\begin{array}{c}\text { Temperature } \\
{[\mathrm{K}]}\end{array}$ & $\begin{array}{c}\rho \\
{[\mathrm{kg} / \mathrm{m} 3]}\end{array}$ & Repetitions & Repetitions & Rate \\
\hline Atmospheric & 1 & 298 & 1.2 & 75 & 0 & $100 \%$ \\
\hline 53900 & 53 & 900 & 20.8 & 75 & 32 & $57 \%$ \\
\hline 43700 & 43 & 765 & 21.7 & 75 & 10 & $87 \%$ \\
\hline 53800 & 53 & 800 & 23.4 & 75 & 19 & $75 \%$ \\
\hline 53700 & 53 & 765 & 26.7 & 75 & 0 & $100 \%$ \\
\hline 63700 & 63 & 765 & 31.8 & 75 & 4 & $95 \%$ \\
\hline
\end{tabular}

Table 5 - Overall plasma induction success rate resumed for all the tested ambient conditions. The reported pressure, temperature and density values, excluding the atmospheric case, are always referred to Top Dead Center position in the engine cycle. 

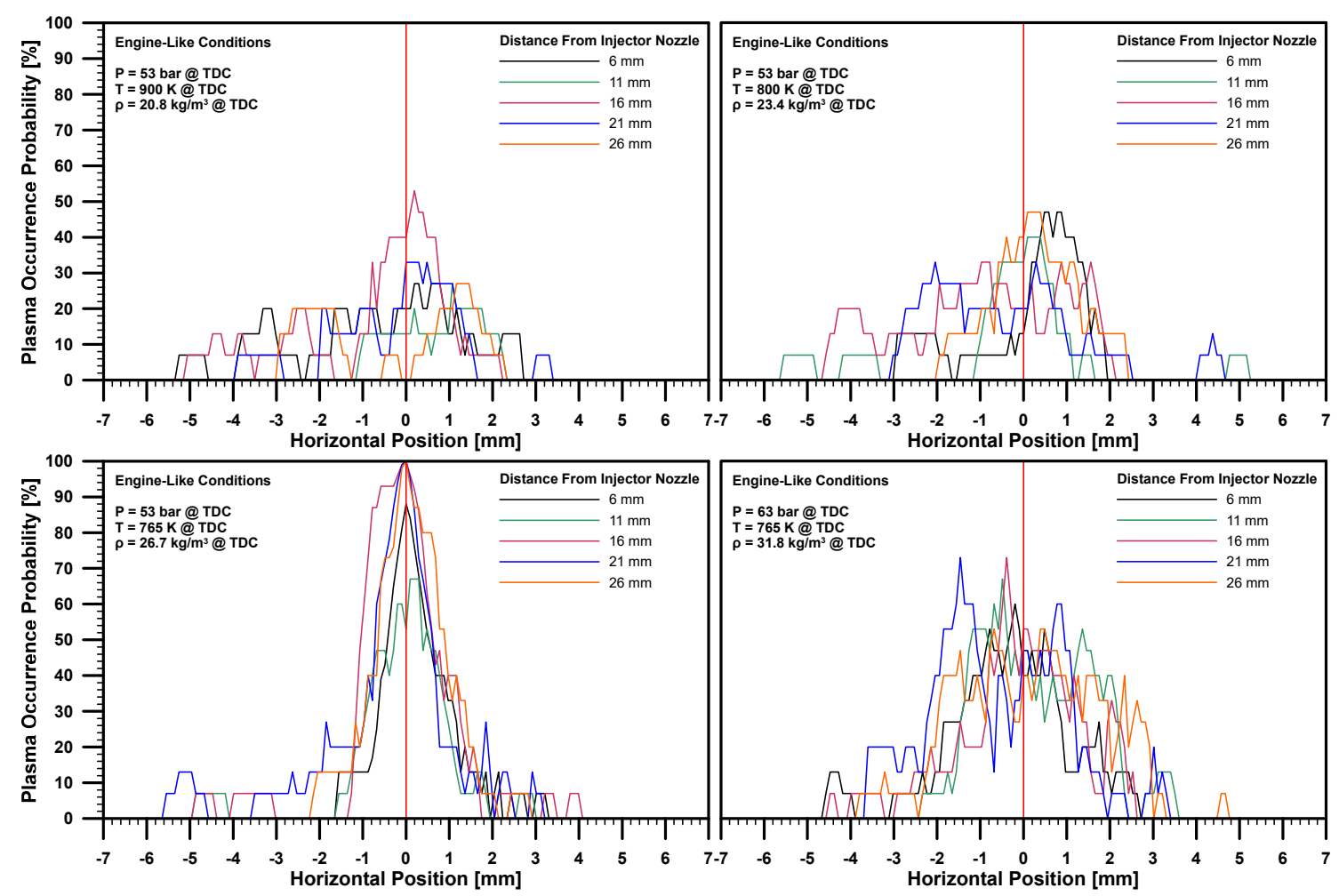

Figure 12 - Plasma Generation Probability for pressure and temperature variations under engine-like conditions are reported. For every engine-like tested conditions the plasma induction was attempted at five different generation location along the injector axis, at 6, 11, 16, 21, $26 \mathrm{~mm}$ from the injector nozzle. The $0 \mathrm{~mm}$ position in the graphics represents the injector axis position in the combustion chamber.

Observing both results in terms of absolute overall effectiveness and positional stability, an important loss in effectiveness in the transition from atmospheric to engine conditions can be appreciated. Applying the induction system to the lowest density case, 53 bar $900 \mathrm{~K} 20.8 \mathrm{Kg} / \mathrm{m}^{3}$, has caused a $43 \%$ effectiveness loss of the induction process if compared to the results obtained in atmospheric conditions, even though a high density ambient should be theoretically more favorable to the induction process due to a lower breakdown threshold of the media. 

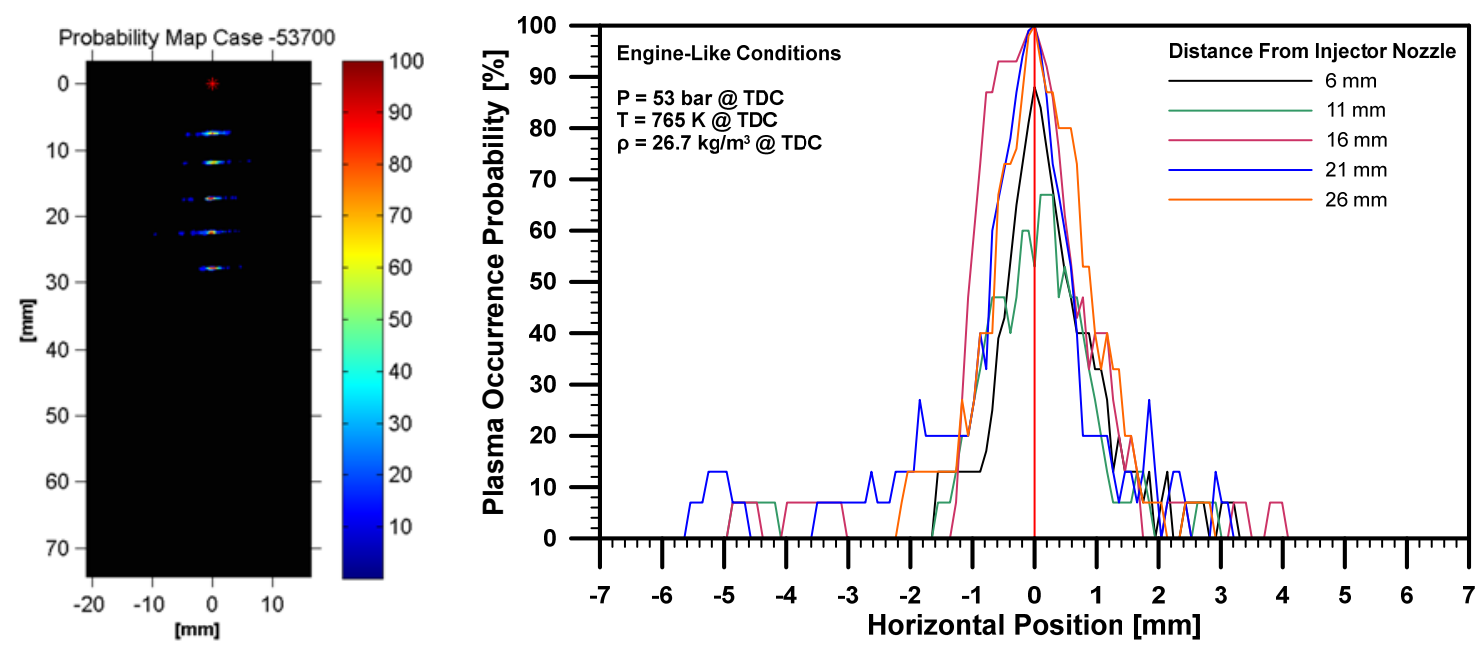

Figure 13 - Plasma probability map (left) and detailed Plasma Occurrence Probability (right) at the focal axis of each respective tested distance from the injector nozzle for the Engine condition case of 53 bar and $765 \mathrm{~K}$ at the TDC, finally selected as test case for the ignition attempts thanks to the possibility to obtain full success rate at different distance with minimum positional variation if compared with the other cases reported.

For this reason the observed effectiveness loss is considered to be related only to the laser focusing process. When the engine is running, both the density gradient and the air movement inside the combustion chamber lower the ability of the optical system to focus the beam in a sufficient small spot, which overcomes the advantage of a lower energy threshold for the plasma breakdown. This leads to the observed decrease in the induction effectiveness. Moreover, from the plasma probability maps shown in Figure 12 , a large variation in the positional stability can be appreciated. If compared to the atmospheric ambient test, every single engine like tested conditions shows a greater "plasma probability area", indicating the possibilities to find plasma in the chamber farther away from the theoretical focal position of the beam on the spray axis.

The parametric study has shown that the best thermodynamics configuration for the ignition tests realization was the one with $700 \mathrm{~K}$ and 53bar in the cylinder at the TDC, at which the highest positional stability and overall effectiveness of the induction process could be appreciated, Figure 13. In fact, among all the tested engine conditions, it was the only one that still presents local areas of $100 \%$ probability of plasma generation. 
Considering the reported results, we can distinguish two potential factors for the observed difference among the probability maps for different conditions. The first one is density, which is the most influencing factor for breakdown occurrence, even though literature such variations are most commonly related to ambient pressure. In this sense, Table 5 demonstrates that by changing temperature at constant pressure one can observe a variation in induction success rate, which demonstrates the role of density rather than pressure as a governing factor.

The parametric variation has also shown how, starting from the lowest density condition, both the overall effectiveness in the plasma generation and the positional stability increases with the ambient density until it reaches $100 \%$ at $26.7 \mathrm{~kg} / \mathrm{m}^{3}$. After this point there is a slight reduction in the success rate $(95 \%)$ at the highest tested density of $31.5 \mathrm{Kg} / \mathrm{m}^{3}$ and a more disperse induction position. This put in evidence the second factor influencing the results, namely the beam steering effect, i.e. light deviation due to density gradietnts, which is limiting the performance of the beam focusing process at high density. This makes it more difficult to accumulate energy at the focal point effect, and the difficulty increases with higher temperature and density, eventually offsetting the previously discussed decrease in energy breakdown threshold at higher density. As a result, at the highest density case even if the energy breakdown threshold is lower, the energy density accumulation is also worse. This takes the system near the limit of the breakdown event occurrence. A worsen beam focusing also implies a higher local focal volume. This is reflected in a bigger focal spot diameter, but also in terms of a bigger depth of focus, which is a measure of the focal volume in the direction of the lens focal axis. This effect, together with the lowered energy threshold and the air movement could be an explication of the observed loss in the plasma induction positional stability and of the large spatial variation observed in the plane containing the focal axis. This fact becomes clear considering the 53700 case, for which even if a $100 \%$ success 
rate is obtained, only few and very small zones of local $100 \%$ plasma probability could be seen in the map.

Another interesting fact to report is the appearance of multi-point induction events during the tests, an example of which is reported in Figure 14. This events occurs for the same reason as reported before. When local energy density is far over the breakdown limit, there will be a higher probability that a molecule in the focal point reaches breakdown randomly. Anyhow this stills does not explain how the registered success rate decreases for the 63700 case once $100 \%$ success is reached in the 53700 case, even if the thermodynamic conditions should be more favorable. Since the purpose of these preliminary tests was to ensure the possibility to reach a plasma generation stability of $100 \%$, the fact of losing effectiveness was not further investigated in this work but, referring to Picket's analysis [36], we can generally justifty such behavior as due to additional interactions effects between the quartz optical access window and the laser radiation. These interactions should be caused by the behavior of the quartz material subject to mechanical and thermal stresses, as it happens along an engine cycle, which can provoke a variation of its optical properties interfering with the beam focusing and so lowering the obtainable local energy density.

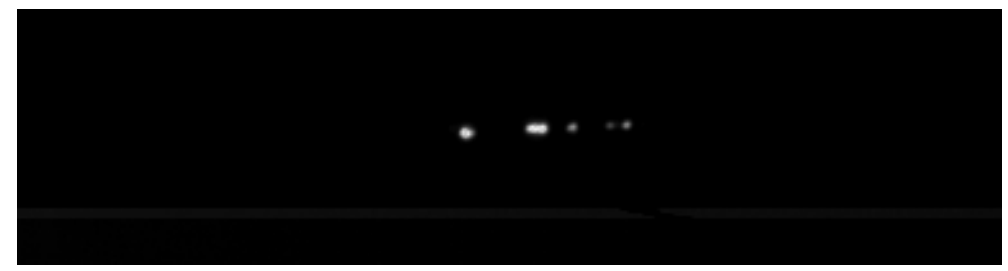

Figure 14 - Example of Multipoint Plasma Induction registered for the condition of 63bar and $700 \mathrm{~K}$ at $6 \mathrm{~mm}$ from the injector Nozzle.

In conclusion, this preliminary study aimed at the optimization of the experimental thermodynamics and optical conditions, has permitted to select a good configuration for the realization of the ignition tests which ensure laser breakdown repeatability so that differences to found in the subsequent results with fuel injection should be related only to the local flow conditions of the fuel spray. 


\subsection{Laser Plasma Ignition application to a direct injected Diesel Spray.}

Once the parametric study for the optimization and quantification of the system effectiveness in the plasma induction has been performed, the best engine conditions combination was selected for the realization of ignition tests on a direct injected Diesel spray. This section reports the results obtained.

Before the application of the ignition system to the spray, a series of auto-ignition tests were realized to determine reference conditions in terms of auto-ignition delay, auto-ignition position and heat release. For these reference tests 200 different auto-ignition repetitions were registered for each optical setup, with a total amount of 400 valid repetitions for the ignition delay determination from the pressure curves analysis.

Once the reference for the Diesel auto-ignition characteristics at the selected engine conditions were determined, a set of 200 tests for the provoked ignition with laser induced plasma were realized. The laser was synchronized to be fired $0.8 \mathrm{~ms}$ ASOE. Taking in account that the first registered auto ignition event does not occurs until $2.2 \mathrm{~ms}$ ASOE, the selected plasma induction timing was early enough with respect the auto-ignition event to permit a clear distinguish between the two combustions, and not too early to have a local condition in the induction point of a too high air/fuel ratio that will have made impossible the success of the ignition attempts.

It can be concluded from the tests that the laser plasma ignition system works, and it has been able to ignite the fuel spray with a success rate of the $100 \%$. Two different combustion cycles as recorded with the Schlieren visualization method, with and without plasma ignition, are shown in 
Figure 15. The plasma spark in the spray is visible in the third picture of Figure 15 taken at 1397us ASOE. In the fourth picture, registered at 1835us ASOE, the combustion process for the provoked ignition test is already started (the spray angle is increased) but not for the auto-ignition case, which happens at 2960us ASOE. Figure 16 reports the ignition timing differences between the auto-ignition and laser plasma provoked ignition for the investigated conditions on a cycle-to-cycle basis, which confirms the previously commented ignition success rate.

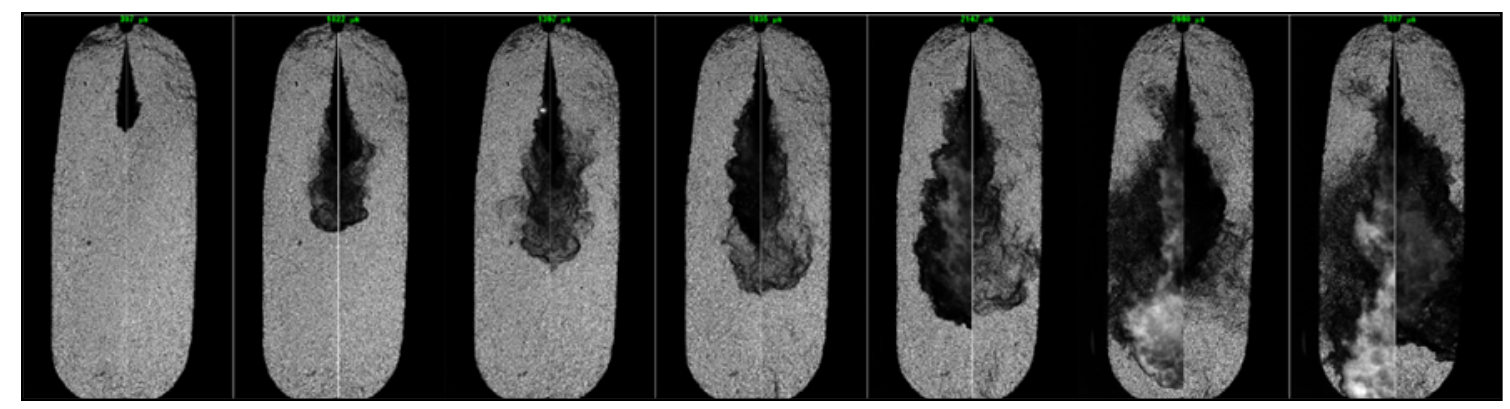

Figure 15 - Combustion comparison evolution between a provoked ignition attempts with a laser plasma system (left) and a natural auto-ignition event of Diesel spray (right). In the picture 3, registered @1397us ASOE, the plasma spark is clearly visible in the spray.

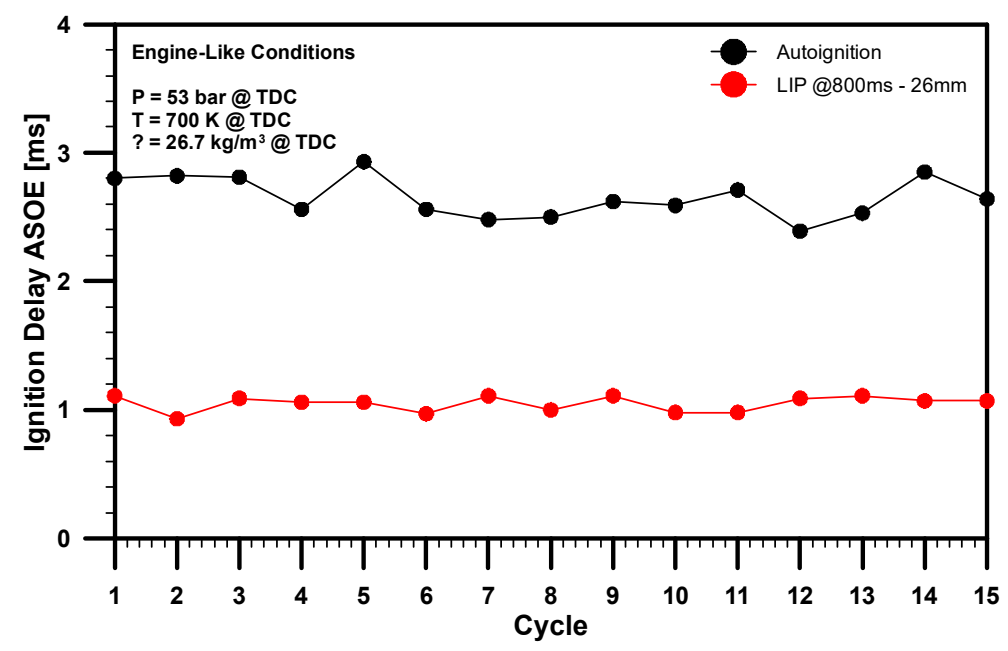

Figure 16 - Ignition Delay analysis between provoked ignition and auto-ignition of a Diesel direct injection spray. The Ignition Delay obtained from the in-chamber pressure signal is showed cycle by cycle comparing the auto-ignition event with the provoked laser plasma ignition generated at $800 \mathrm{~ms}$ ASOE and at $26 \mathrm{~mm}$ from the injector nozzle position

Moreover, besides the system effectiveness in the ignition event, a stabilization of the laser ignition can be noted. In fact, in Figure 16 the ignition delay in the provoked laser plasma ignition 
case is clearly seen to be dominated by the plasma induction timing, if compared with the autoignition reference, leading to less variation in the ignition timing.

Considering the images shown in Figure 17, the effect of the spatial position of the induced plasma on the combustion development could also be evaluated and compared with the auto-ignition event.

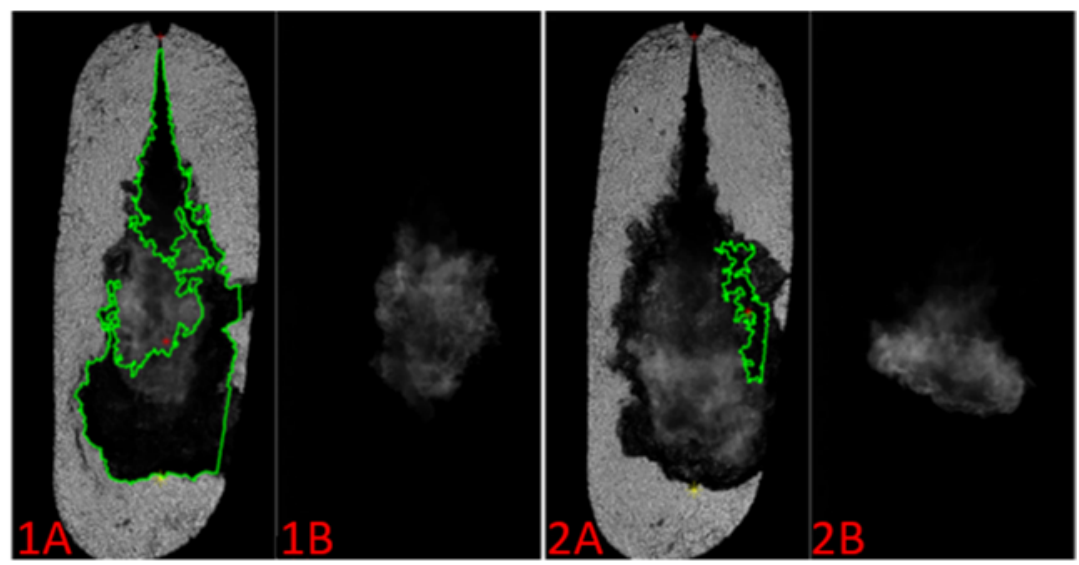

Figure 17 - Comparison between the soot cloud position in laser plasma provoked ignition (left - Image 1) and auto-ignition (right Image 2). Pictures (a) of both images are obtained by the Schieren method combustion visualization while (b) pictures are obtained by the Natural Luminosity visualization technique. With both methods is possible to visualize the soot radiation in the spray and so infer the position where the combustion has started.

From the images the soot cloud broadband light emission is observed to be located at the fuel spray tip, where the conditions are feasible to start the ignition of the mixture and therefore the soot formation. In the case of the provoked laser plasma ignition, the laser plasma position for this tests was fixed at $16 \mathrm{~mm}$ from the spray nozzle. Such a location was chosen taking into consideration that the spray should have reached it, but local air/fuel ratio conditions should not be critical for the ignition. Compared to the natural autoignition case, where soot cloud is first generated at the spray tip, in the laser-ignited case the reacted zone, where soot radiation is present, occurs at first around the plasma induction location and not at the spray tip, where the spray can still be seen to progress. 


\section{SUMMARY AND CONCLUSIONS}

A method for quantification, control and optimization of the reliability and effectiveness of a laser induced plasma ignition system (LIP) has been tested experimentally in an optical test rig by using Schlieren and Natural Luminosity visualization techniques. In addition, the usefulness of the LIP system to provoke fuel ignition and stabilize combustion has been also demonstrated in a real Diesel spray.

Regarding LIP system, a first optical design of the elements needed for the realization of a laser plasma induction system was performed starting just from literature. Then, the laser pulse energy was optimized to limit the total amount of energy density generated at the focal spot. For this optimization purpose, laser induced plasma was generated in two different environments, sequentially:

- Atmospheric conditions: In order to define a methodology to ensure the required reliability of the induction system for engine combustion parametric studies, probability maps are created from plasma images allowing the quantification of the overall efficiency and positional stability of the induced plasma for each test. Thus, LIP system settings were defined to ensure full success rate $(100 \%)$ in terms of plasma generation for a range of engine environment thermodynamic conditions. Moreover, an optimal positional stability, guaranteeing the induction of the breakdown just in the region where the spray axis will be in further experiments, is also attained in all the induction attempts, with a laser beam of $300 \mathrm{~mJ}$ power peak, emitted at $1064 \mathrm{~nm}$ and focused through a plano convex n-BK7 lens of $300 \mathrm{~mm}$ focal length. 
- Engine-like conditions: in-cylinder pressure and temperature conditions have been varied in an optical test rig to reproduce real engine density conditions, ranging from 20.8 to 31.8 $\mathrm{Kg} / \mathrm{m}^{3}$. By applying the previously developed methodology of probability maps, the following conclusions have been drawn:

o Compared to the results at atmospheric air, the engine-like condition of $20.8 \mathrm{~kg} / \mathrm{m}^{3}$ has shown a $43 \%$ loss in the system effectiveness to induce plasma, even though the higher density should be favorable for the breakdown event. This behavior is due to a high decay in the system focusing ability due a strong beam steering effect induced by both the internal air flow and the refraction index variation in the last part of the focusing beam path.

o Different induction success rate values were obtained for different chamber densities from $56 \%$ at $20.8 \mathrm{~kg} / \mathrm{m}^{3}$ to $100 \%$ at $26.7 \mathrm{~kg} / \mathrm{m}^{3}$. Thus, higher densities imply higher success rate, permitting to reach full success rates. Consequently, the increase of the air density seems to be the main parameter governing the laser induced breakdown success.

o Positional stability of the induced plasma, is also affected by the density variations, as shown in the reported probability maps and graphs. In particular, the lowering effect of the breakdown energy threshold with the increase of the local density leads to an "overkill" condition for the $31.8 \mathrm{~kg} / \mathrm{m}^{3}$ case. In this condition the local energy density is far beyond that needed for the plasma induction, meaning that a bigger local volume contains enough energy to provoke a breakdown. In this condition, the stochastic nature of the breakdown event imply that randomly any molecule contained within this volume could break-up, generating the electron 
cascade that leads to the plasma induction and so lowering the positional stability of the ignition system and its general reliability.

Under engine-like condition of 53 bar $765 \mathrm{~K}$ and $26.7 \mathrm{~kg} / \mathrm{m}^{3}$ at TDC with full induction success rate, LIP system was applied to ignite a direct injected Diesel spray. Thus, the previous optimized LIP system has revealed also full ignition success rate at the conditions tested in this work. Moreover, the LIP system has shown to provide temporal and spatial control on the combustion process, if compared with the case of conventional auto-ignition of the Diesel spray:

- Temporal control: the main parameter considered for the determination of the temporal control of the system over the combustion event is the ignition delay, which can be quantified from both the in-cylinder pressure and from combustion visualization images. In every single cycle fired with the LIP ignition system at $0.8 \mathrm{~ms}$ ASOE and $26 \mathrm{~mm}$ from the injector nozzle, combustion has been observed to start earlier than in the auto-ignition reference conditions (1.1 ms compred to $2.9 \mathrm{~ms}$ ASOE, respectively). Moreover, igniting the spray with the LIP system also leads to less variations in the ignition delay times.

- Spatial control: evidences obtained from the Schlieren and Natural Luminosity combustion visualization techniques have shown how the LIP induced combustion occurs closer to the injector nozzle. It was shown that, for the plasma induced ignition conditions tested, the soot cloud is generated inside the spray cone, near the plasma induction position, and not at the spray tip as occurs in an auto-ignition event.

\section{ACKNOWLEDGMENTS}

The authors acknowledge that this research work has been partly funded by the Spanish Economy and Competitiveness Ministry under the project HiReCo TRA2014-58870-R and grant BES-2015- 
072119. The equipment used in this work has been partially supported by FEDER project ICTS-2012-

06, framed in the operational program of unique scientific and technical infrastructure of the Ministry of Science and Innovation of Spain.

\section{REFERENCES}

[1] H. Yanagihara, Y. Sato and J. Minuta, "A simultaneous reduction in NOx and soot in diesel engines under a new combustion system (Uniform Bulky Combustion Systems - UNIBUS)," in 17th International Vienna Motor Symposium, 1996.

[2] J. Benajes, J. V. Pastor, A. García and J. Monsalve-Serrano, "An experimental investigation on the Influence of piston bowl geometry on RCCl performance and emissions in a heavy-duty engine," Energy Conversion and Management, vol. 103, pp. 1019-1030, October 2015.

[3] S. Kimura, S. Aoki, Y. Kitahara and E. Aiyoshizawa, "Ultra-clean Combustion Technology Combining a Low-temperature and Premixed Combustion Con- cept for Meeting Future Emission Standards," SAE International, 2001.

[4] J. Benajes, A. García, V. Domenech and R. Durrett, "An investigation of partially premixed compression ignition combustion using gasoline and spark assistance," Applied Thermal Engineering, no. 52, pp. 468-477, 2013.

[5] J. Benajes, S. Molina, A. García and J. Monsalve-Serrano, "Effects of Direct injection timing and Blending Ratio on RCCl combustion with different Low Reactivity Fuels," Energy Conversion and Management, vol. 99, pp. 193-209, July 2015.

[6] H. Zhao, $\mathrm{HCCl}$ and CAl Engines for the Automotive Industry, Cambridge,: Woodhead Publishing, 2007.

[7] W. Piock, P. Weyand, E. Wolf and V. Heise, "Ignition Systems for Spray-Guided Stratified Combustion," SAE Int. J. Engines, vol. 3, pp. 389-401, 2010.

[8] T. Fansler, M. Drake and B. Böhm, "High-Speed Mie-Scattering Diagnostics for Spray-Guided Gasoline Engine Development," Proceedings of the 8th International Symposium on Internal Combustion Engine Diagnostics, June 2008.

[9] R. Dahms, T. Fansler, M. Drake, T. Kuo, A. Lippert and N. Peters, "Modeling ignition phenomena in spray-guided spark-ignited engines," Proceedings of the Combustion Institute, no. 32, pp. 2743-2750, 2009.

[10] B. Peterson, R. D.L. and V. Sick, "High-Speed Imaging Analysis of Misfires in a Spray-Guided Direct Injection Engine," Proceedings of the Combustion Institute, 2010. 
[11] M. Febler, M. Wetzel, M. Schenk, H. Rottengruber and W. Huhn, "Determination of Thermodynamic Potentials for Alternative Ignition Systems in Spray-Guided Combustion," Proceedings of the 8th International Symposium on Internal Combustion Engine Diagnostics, June 2008.

[12] M. Drake, T. Fansler and A. Lippert, "Stratified-charge combustion: modeling and imaging of a sprayguided direct- injection spark-ignition engine," Proceedings of the Combustion Institute, no. 30, pp. 2683-2691, 2005.

[13] J. D. Dale, M. D. Checkel and P. R. Smy, "Application of High Energy Ignition Systems to Engines," Prog. Energy Combust. Sci., no. 23, pp. 379-398, 1997.

[14] P. D. Ronney, "Laser versus conventional ignition of flames," Optical Engineering, no. 33(2), p. 510, 1994.

[15] P. Y. Raizer, "Heating of a gas by a powerful Ight pulse," Sov Phys JETP, vol. 17, p. 21:1009, 1965.

[16] L. JH. and K. R., "Laser spark ignition of chemical reactive gases," AIAA J, vol. 7, p. 7:312, 1969.

[17] H. Kopecek, E. Wintner, R. Pischinger, G. Herdin and J. Klausner, "Basics for a Future Laser Ignition system for Gas Engines," ASME 2000-ICE, Vols. 35-2.

[18] T. X. Phuoc, "Laser spark ignition: Experimental determination of laser-induced breakdown thresholds of combustion gases," Optics Communications, vol. 175, no. 4, pp. 419-423, 2000.

[19] L. Radziemski and D. Cremers, "Laser-Induced Plasmas and Applications," 1989.

[20] F. Weinberg and J. Wilson, "F.J. Weinberg, J.R. Wilson: "A Preliminary Investigation of the Use of Focused Laser Beams for Minimum Ignition Energy Studies," Proc. Roy. Soc., vol. A, no. 321, pp. 41-52, 1971.

[21] J.D.Dale, P. Smy and R. Clements, "Laser Ignited Internal Combustion Engine - An Experimental Study," SAE, 1978.

[22] D. Bradley, C. Sheppard, I. Suardjaja and R. Woolley, "Fundamentals of High-Energy Spark Ignition with Lasers," Combustion and Flame, no. 138, pp. 33-77, 2004.

[23] M. Weinrotter, E. Wintner, K. Iskra, T. Neger, J. Olofsson, H. Seyfried, M. Aldén, M. Lackner, F. Winter, A. Vressner, A. Hultqvist and B. Johansson, "Optical Diagnostics of Laser-Induced and Spark PlugAssisted HCCl Combustion," Homogeneous Charge Compression Ignition (HCCl) Combustion 2005 (SP1963), 11-14 April 2005.

[24] M. H. Morsy, "Review and recent developments of laser ignition for internal combustion engines applications," Renewable and Sustainable Energy Reviews, no. 16, pp. 4849-4875, 2012.

[25] L. M. Pickett, A. A. Hoops and J. M. Headrick, "Laser Ignition of multi-injection gasoline sprays," SAE Technical Paper, no. 2011-01-0659, pp. 1-26, 2011.

[26] V. Bermúdez, J. García, E. Juliá and S. Martínez, "Engine with Optically Accessible Cylinder Head: A Research Tool for Injection and Combustion Processes," 2003.

[27] J. V. Pastor, J. M. Garcia-Oliver, V. Bermudez and C. Micó, "Spray Characterization for Pure Fuel and Binary Blends under Non-Reacting Conditions," 2014. 
[28] J. M. Desantes, J. V. Pastor, J. M. García-Oliver and F. J. Briceño, "An experimental analysis on the evolution of the transient tip penetration in reacting Diesel sprays," Combustion and Flame, no. 161, pp. 2137-2150, 2014.

[29] J. X. Ma, D. R. Alexander and D. E. Poulain, "Laser Spark Ignition and Combustion Characteristics of Methane-Air Mixtures," Combustion And Flame, vol. 112, pp. 492-506, 1998.

[30] J. L. Beduneau, B. Kim, L. Zimmer and Y. Ikeda, "Measurements of minimum ignition energy in premixed laminar methane/air flow by using laser induced spark," Combustion and Flame, vol. 132, no. 4, pp. 653-665, 2003.

[31] T. Phuoc and F. White, "Laser induced spark ignition of $\mathrm{CH} 4 /$ air mixtures," Combustion and Flame, no. 119, pp. 203-216, 1999.

[32] G. Weyl, L. Radziemsky and D. Cremers, Phsics of laser-induced breakdown: an update, in Laserinducted plasma applications, M. Dekker, Ed., New York, 1989, p. 1.

[33] Y. Chen, J. Lewis and C. Parigger, "Spatial and temporal profiles of pulsed laser-induced air plasma emissions," J. Quant. Spectrosc. Radiat. Transfer,, no. 67, pp. 91-103, 2000.

[34] J. Syage, E. Fournier and R. Rianda, "Dynamics of flame propagtion using laser-induced spark initiation: Ignition Energy measurements," Journal of Applied Phisics, no. 64, p. 1499, 1988.

[35] T.-W. Lee, V. Jain and S. Kozola, "Measurements of Minimum Ignition Energy By Using Laser Sparks for Hydrocarbon Fuels in Air : Propane, Dodecane, and Jet-A Fuel," Combustion and Flame, vol. 125, pp. 1320-1328, 2001.

[36] L. M. Pickett and M. P. Musculus, "Diagnostic considerations for optical laser-extinction measurements of soot in high-pressure transient combustion environments," Combustion and Flame, no. 141, p. 371391, March 2005.

[37] H. Liu, P. Zhang, Z. Li, J. Luo, Z. Zheng and M. Yao, "[6] H. Liu, P. Zhang, Z. Li, J. Luo, Z. Zheng, M. Yao, Effects of temperature in- homogeneities on the $\mathrm{HCCl}$ combustion in an optical engine," Applied Thermal Engineering, vol. 31, pp. 2549-2555, 2011. 